\title{
Granulation of Fe-Al-Ce hydroxide nano-adsorbent by immobilization in porous polyvinyl alcohol for fluoride removal in drinking water
}

\author{
Hai-Xia Wu ${ }^{\text {a }}$, Ting-Jie Wang ${ }^{\mathrm{a}, *}$, Lin Chen ${ }^{\mathrm{a}}$, Yong Jin ${ }^{\mathrm{a}}$, Yu Zhang ${ }^{\mathrm{b}}$, Xiao-Min Dou ${ }^{\mathrm{c}}$ \\ a Department of Chemical Engineering, Tsinghua University, Beijing 100084, China \\ ${ }^{\mathrm{b}}$ Research Center for Eco-Environmental Sciences, Chinese Academy of Sciences, Beijing 100085, China \\ c School of Environmental Science and Engineering, Beijing Forestry University, Beijing 100083, China
}

\section{A R T I C L E I N F O}

\section{Article history:}

Received 24 July 2010

Received in revised form 18 December 2010

Accepted 11 February 2011

Available online 18 February 2011

\section{Keywords:}

Granulation

Adsorbent

Polyvinyl alcohol

Fluoride removal

Water treatment

\begin{abstract}
A B S T R A C T
Nano-adsorbents of Fe-Al-Ce trimetal hydroxide (FAC) were immobilized in porous polyvinyl alcohol (PVA) via cross-linking with boric acid. Spherical composite granules of 3-5 $\mathrm{mm}$ in size that would not cause a large pressure drop in a packed bed were obtained. SEM images showed that the FAC particles were embedded in holes of about $10 \mu \mathrm{m}$ in the PVA granules, while the surface pores of the granules were only nano-scale in size. Thermal analysis showed that the FAC and PVA in the granules combined tightly by forming a chemical bond. The mechanical stability of the granules decreased with increased FAC concentration, and increased with increased PVA concentration. The fluoride adsorption capacity of the granules increased with FAC concentration and decreased with PVA concentration. For acceptable mechanical stability and adsorption capacity, a FAC concentration of $12 \%$ and PVA concentration of $7.5 \%$ were suggested. The adsorption capacity of the granules prepared under suggested concentrations was $4.46 \mathrm{mg} / \mathrm{g}$ at an initial fluoride concentration of $19 \mathrm{mg} / \mathrm{L}$ and $\mathrm{pH}$ 6.5. Immobilization of the nano-adsorbent in porous polyvinyl alcohol granules is a promising granulation method for water treatment in packed beds.
\end{abstract}

(C) 2011 Elsevier B.V. All rights reserved.

\section{Introduction}

High concentration of fluoride above $1 \mathrm{mg} / \mathrm{L}$ in drinking water will easily causes dental and skeletal fluorosis [1], and WHO give a guide limitation of less than $1.5 \mathrm{mg} / \mathrm{L}$ [2]. Adsorption is considered one of the most efficient technologies for fluoride removal in drinking water when compared with other technologies like reverse osmosis [3], nanofiltration, electrodialysis [4] and Donnan dialysis [5]. Many kinds of adsorbents have been investigated for efficient and economical defluoride removal. The most commonly used adsorbents are activated alumina and activated carbon. However, they have low adsorption capacity, poor physical integrity, require acidification and pretreatment and their effectiveness for fluoride removal reduces after each regeneration [1]. As natural materials cannot meet industrial requirements, i.e., low cost and high adsorption capacity, manmade adsorbents have been developed. However, most adsorbents are synthesized as fine powders or hydroxide floc [6]. Ultra-fine powder adsorbents cannot be used directly for water treatment because of their low hydraulic conductivity (high pressure drop) [7] in packed bed as well as in leaching, and because these adsorbents would have to be used in devices that make the separation and recycling of the adsorbent difficult and costly. In a packed bed, an

\footnotetext{
* Corresponding author. Tel.: +86 10 62788993; fax: +86 1062772051. E-mail address: wangtj@tsinghua.edu.cn (T.-J. Wang).
}

increase in the size of the granules can increase the hydraulic conductivity [8]. Therefore, powder granulation to produce granules with high mechanical stability is necessary for practical application.

Conventional granulation of powder adsorbents includes molding and calcination. However, calcination at high temperature results in a low adsorption capacity of the granules because many active sites on the adsorbent surface may be passivated. A Fe-Al-Ce trimetal hydroxide adsorbent (FAC) was reported to have high adsorption capacity. After this was granulated to $1 \mathrm{~mm}$ pellets, the adsorbent still showed promising performance in column experimental tests [6].

A granulation method that used an iron oxide adsorbent coating on a particle carrier to remove toxic ions in drinking water has been reported. This could be operated in packed beds and it reduced the cost of the adsorbent $[9,10]$. The fluoride adsorption capacity for manganese-oxide-coated alumina (MOCA) reached $2.85 \mathrm{mg} / \mathrm{g}$ [11]. However, the coated layer shed easily leaving the granules with little adsorption capacity, and caused secondary pollution to the drinking water because of its low mechanical stability. At the same time, the ratios of coated-layer to carrier were below $1 \%$ in the reported literature [12-14], which greatly limited the adsorption capacity of the coated adsorbent particles. Copolymer latex has been introduced as a binder to reinforce the bonding between adsorbent and carrier. The coating stability and adhesion strength of the adsorbent layer on the carrier were improved [15].

An ideal adsorbent granulation process should produce granules with the optimal size and porous structure to give a packed bed with a 
higher hydraulic conductivity and large surface area. The polymer encapsulation technique can provide porous structures that allow substrates to diffuse rapidly into the internal pores, which are often used for cell immobilization [16-19]. Polyvinyl alcohol (PVA) is a cheap and nontoxic synthetic polymer, and its granules can meet the mechanical stability requirements of waste water treatment [20].

This work studied granulation by immobilizing FAC in porous polyvinyl alcohol granules to increase hydraulic conductivity in packed bed. The feasibility of using PVA as a matrix for the granulation of FAC, and the FAC and PVA concentration effects on mechanical stability and fluoride adsorption capacity were investigated.

\section{Experimental}

\subsection{Materials}

$\mathrm{FeSO}_{4} \cdot 7 \mathrm{H}_{2} \mathrm{O}, \mathrm{Al}_{2}\left(\mathrm{SO}_{4}\right)_{3} \cdot 18 \mathrm{H}_{2} \mathrm{O}$ and $\mathrm{Ce}\left(\mathrm{SO}_{4}\right)_{2} \cdot 4 \mathrm{H}_{2} \mathrm{O}$ used were analytical grade (Chemical Engineering Company of Beijing, China). The polymerization degree of the PVA used was 1700 and the approximate molecular weight of the PVA was about 74800, and the saponification ratio was 99\% (Beijing Yili Fine Chemicals Co., Ltd, China). The other chemicals used were analytical reagent (AR) grade.

\subsection{FAC preparation}

$\mathrm{FeSO}_{4} \cdot 7 \mathrm{H}_{2} \mathrm{O}, \mathrm{Al}_{2}\left(\mathrm{SO}_{4}\right)_{3} \cdot 18 \mathrm{H}_{2} \mathrm{O}$ and $\mathrm{Ce}\left(\mathrm{SO}_{4}\right)_{2} \cdot 4 \mathrm{H}_{2} \mathrm{O}$ were dissolved in deionized water to form a mixed solution with concentrations of $0.1 \mathrm{M}, 0.2 \mathrm{M}$ and $0.1 \mathrm{M}$, respectively. $6 \mathrm{M} \mathrm{NaOH}$ solution was slowly titrated into the mixed solution until the $\mathrm{pH}$ was 9.5. The solution was stirred at $200 \mathrm{rpm}$ during the whole process [6]. The precipitates obtained were centrifuged and washed with deionized water until the $\mathrm{pH}$ of the filtrate was $6.5 \pm 0.2$. The product FAC of trimetal hydroxide nano-adsorbent was kept in deionized water.

\subsection{Granulation process}

The granulation was carried out referring to the reported immobilization procedure $[21,22]$. First, the PVA was dissolved in deionized water at a set concentration and at $95{ }^{\circ} \mathrm{C}$ with stirring. Second, the FAC suspension and PVA solution were mixed to form a suspension for granulation. Third, boric acid was added to $20 \mathrm{~g} / \mathrm{L}$ calcium chloride solution to form a saturated boric acid solution that was used as the crosslink reagent. Fourth, the mixed suspension of FAC and PVA was dropped into the boric acid solution for cross-linking and immobilization. The gel granules were kept in the boric acid solution at $20^{\circ} \mathrm{C}$ for several hours in order to achieve sufficient crosslinking between PVA and boric acid. Then, the granules were washed, dried at room temperature and kept in a capped bottle. The reaction between the boric acid and PVA molecular is depicted in the following equation. The concentration of boric acid and PVA both affect the cross-linking process.

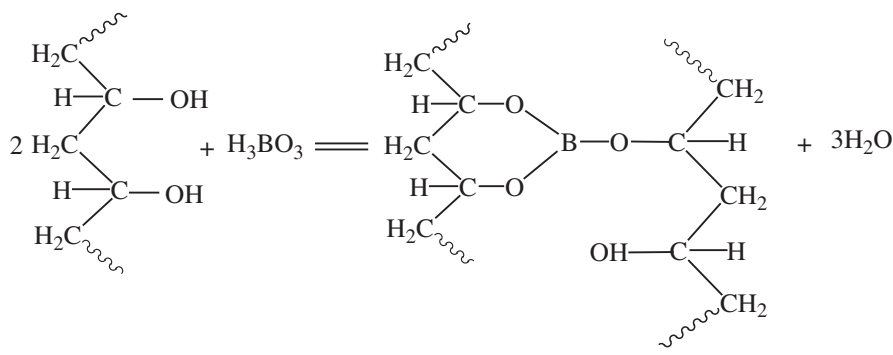

In addition, the sapoinfication ratio of PVA should be over 99\% for a high stability of the PVA granules, and this high stability can be maintained even when the granules are soaked in high $\mathrm{pH}$ solution over two months.

\subsection{Fluoride adsorption test [6]}

The fluoride solution was prepared by dissolving $\mathrm{NaF}$ (analytical grade) in deionized water at a concentration of $0.001 \mathrm{~mol} / \mathrm{L}(19 \mathrm{mg} / \mathrm{L})$ according to the concentration order of the fluoride-contaminated underground water. The adsorbent granule dose was $2 \mathrm{~g} / \mathrm{L}$. The volume of the fluoride solution was $100 \mathrm{~mL}$. The $\mathrm{pH}$ of the test solution was adjusted by $0.05 \mathrm{M} \mathrm{HNO}_{3}$ or $0.05 \mathrm{M} \mathrm{NaOH}$ solution until it reached to 6.5 . The solution was shaken at $100 \mathrm{rpm}$ and at $25^{\circ} \mathrm{C}$ during the adsorption process. The fluoride ion concentration of the solution was measured with a fluoride selective electrode connected to an ion meter (PXS-450, Shanghai Kang-Yi Instruments Co., LTD, China) during the adsorption process for over $20 \mathrm{~h}$, after which the granules reached the adsorption equilibrium.

The adsorption capacity, $\mathrm{q}_{\mathrm{e}}(\mathrm{mg} / \mathrm{g})$, was calculated using the following equation:

$\mathrm{q}_{e}=\frac{C_{0}-C_{f}}{m} \times V$

where $C_{0}(\mathrm{mg} / \mathrm{L})$ is the initial fluoride concentration of $19 \mathrm{mg} / \mathrm{L}$, $C_{f}(\mathrm{mg} / \mathrm{L})$ is the final fluoride concentration which is measured by the ion meter, $V$ is the volume of the fluoride containing solution of $100 \mathrm{~mL}$, and $m$ is the adsorbent granules dose of $0.2 \mathrm{~g}$.

$\mathrm{KNO}_{3}$ solution with a concentration of $0.2 \mathrm{M}$ was added to the fluoride containing water as the background electrolyte before adsorption. The introduction of electrolyte solution can maintain the sample solution at a same activity coefficient, to eliminate the influence of the different solution ionic strength on the measurement accuracy. The fluoride concentration was measured during the adsorption process at intervals.

However, considering the competition adsorption between $\mathrm{NO}_{3}^{-}$ and fluoride ion on the adsorbent granules during fluoride adsorption, the measured adsorption capacity according to above method was a little lower than the actual adsorption capacity. Therefore, the measured adsorption capacity was calibrated from the following experiments on different kinds of adsorbent granules. $\mathrm{KNO}_{3}$ solution with a concentration of $0.2 \mathrm{M}$ was added to the solution after the adsorption process was completed and the adsorbent granules were filtered, to eliminate the competition effect during adsorption. Then the final fluoride concentrations were recorded by the ion meter. The mean of the raising fluoride ion adsorbed onto the granules in these experiments was about $7 \%$ of the initial amount of the fluoride ion in the water. Therefore, the values of measured adsorption capacity were calibrated by increasing $7 \%$ to approach the actual adsorption capacity.

\subsection{Characterization}

The morphology of FAC was examined by a high-resolution transmission electron microscopy (HRTEM, JEM-2011, JEOL Co., Japan). The morphology and structure of the granules were examined by high resolution scanning electron microscopy (HRSEM, JSM 7401, JEOL Co., Japan). The inner structure of the granule was inspected from the cross-section obtained by cutting the granule (PVA, FAC-PVA) with a sharp knife. The samples were coated with a thin gold layer before HRSEM observation. Thermal behavior of the PVA, FAC and FAC-PVA granules were analyzed by differential scanning calorimetry and thermo-gravimetric analysis (TGA2050, TA Instruments, USA). The samples were kept under $\mathrm{N}_{2}$ protection during the whole heating process to prevent the influence of oxidation. A heating rate of $10{ }^{\circ} \mathrm{C} /$ min was used from 35 to $600{ }^{\circ} \mathrm{C}$. 
The ratio of the mass of FAC shed to the FAC-PVA granules mass was used to characterize the mechanical stability. Granules $\left(m_{1}\right)$ were added to $100 \mathrm{~mL}$ deionized water, and after $24 \mathrm{~h}$ of shaking at $250 \mathrm{rpm}$ in a mechanical shaker, the granules were filtered and dried at $50{ }^{\circ} \mathrm{C}$ for $24 \mathrm{~h}$ to obtain the remaining weight $\left(m_{2}\right)$. The stability of the granules was calculated from $m_{2} / m_{1} \times 100 \%$.

\section{Results and discussion}

\subsection{Granulation process}

The FAC particles were synthesized according to the reported literature. In the reported literature, the adsorption capacity was $178 \mathrm{mg} / \mathrm{g}$ under an equilibrium fluoride concentration of $84.5 \mathrm{mg} / \mathrm{L}$, with an adsorbent dose of $150 \mathrm{mg} / \mathrm{L}$ and at $\mathrm{pH} 7.0$, and the desorption efficiency of fluoride from the used FAC reached $97 \%$ with $\mathrm{NaOH}$ solution at pH 12.2 [6]. Fig. 1 shows that the FAC size was on the nanoscale.

The mixture suspension of FAC and PVA was dripped using a peristaltic pump, and the droplets fell into a boric acid solution to be cross-linked with boric acid. The droplets sank to the bottom of the boric acid solution due to their higher density, and were immobilized in the sinking process.

Droplets contracted to spheres due to the interfacial tension between the drop surface and the immiscible solution [23]. Experiments showed that the drop shape was affected by the drop's physical properties due to the differences in the mixture compositions. Spherical granules of 3-5 mm in size were obtained when the FAC concentration was between 4 and $12 \%$ and the PVA concentration was between 7.5 and 10\%, as shown in Fig. 2 .

When the FAC concentration was between 4 and $12 \%$, and the PVA concentration was between 4 and $7.5 \%$, a tail was formed on the spherical granule. When the FAC concentration was below $4 \%$ and the PVA concentration was below $4 \%$, the suspension drops were difficult to granulate, and they tended to form rings. When the FAC concentration was above $12 \%$, and the PVA concentration was above $10 \%$, the suspension could not form drops due to the high viscosity.

Therefore, the granulation research here used concentrations of $4-12 \%$ for FAC and $4-10 \%$ for PVA. For mass production in the future, the preparation of the granules can be scaled up by numbering up of the nozzles [23].

\subsection{Structure of the granules}

The cross-linking process was analyzed by sampling the granules at different times. The samples were washed and put in deionized water. The SEM images of the granule surface are shown in Fig. 3. Fig. 3a shows the image of the $10 \mathrm{~min}$ cross-linked granules, and

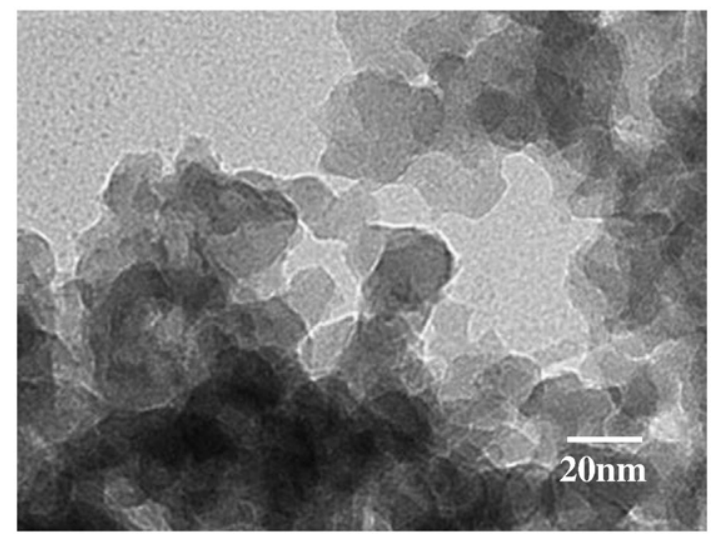

Fig. 1. TEM image of the FAC nano-adsorbent.

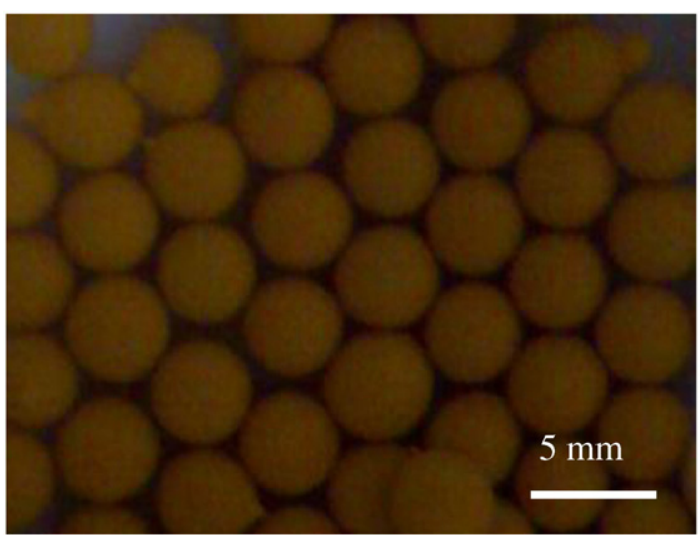

Fig. 2. Spherical granules produced.

showed that the FAC had agglomerated. This occurred because the uncross-linked PVA is easily dissolved in water during washing and leaves the FAC agglomerated as the water evaporated. After $30 \mathrm{~min}$, some cross-linked PVA spots could be seen in Fig. 3b. These spots became more apparent after $2 \mathrm{~h}$ of cross-linking as shown in Fig. 3c. The surface became smooth and formed a film after $6 \mathrm{~h}$ of crosslinking as shown in Fig. 3d. Then the film was further cross-linked and pores formed after $12 \mathrm{~h}$ as shown in Fig. 3e. After $24 \mathrm{~h}$, the PVA in the granules has been sufficiently cross-linked and it formed a porous surface. For high mechanical stability of the granules, a sufficient amount of time is necessary for cross-linking. In the following experiments, the set time for cross-linking was $24 \mathrm{~h}$.

The surface and the cross section structures of a pure PVA granule and FAC-PVA granule after $24 \mathrm{~h}$ cross-linking are shown in Fig. 4. Fig. $4 \mathrm{a}$ and $\mathrm{b}$ shows the outer surface and inner cross section structure of a pure PVA granule, respectively. It can be seen that tiny uniformly distributed pores of nano-scale size were present on the outer surface, while the inner holes in the PVA granules shown as the cross section in Fig. 4b were about $10 \mu \mathrm{m}$, much larger than those on the outer surface. Fig. $4 \mathrm{c}$ and d shows the outer surface and inner cross section structure of the FAC-PVA granules, respectively. It can be seen that the outer surface of FAC-PVA granule has the same sized pores as the pure PVA granules, and the inner holes in the granule as shown in the cross section in Fig. 4d were full of FAC particles.

The larger size of the granules gives the packed bed a high hydraulic conductivity, and the porous structure supports a large surface area for adsorption.

\subsection{Interactions of FAC and PVA}

The interactions between FAC and PVA in the granules were analyzed by their thermal behavior during heating. Fig. 5 shows the curves of weight loss in the PVA, FAC and FAC-PVA granules. In the TGA curve, the cross-linked pure PVA showed mass loss of a few percent below $150^{\circ} \mathrm{C}$, which was assigned to the evaporation of adsorbed water. The PVA lost most of its weight in the range of 240 $500{ }^{\circ} \mathrm{C}$ due to decomposition. The FAC nano-adsorbent lost about $27 \%$ of its mass below $600{ }^{\circ} \mathrm{C}$, which was assigned to the loss of crystal water.

Fig. 6 shows the DSC curves of the PVA, FAC and FAC-PVA granules. Considering the sharp weight loss of pure PVA granules in Fig. 5, an endothermic peak of $240{ }^{\circ} \mathrm{C}$ was assigned to PVA decomposition. The endothermic peak of the FAC adsorbent at $110^{\circ} \mathrm{C}$ was assigned to the evaporation of adsorbed water. The crystal water loss gave the broad endothermic process below $600{ }^{\circ} \mathrm{C}$.

Fig. 6 shows that the endothermic peaks of the FAC-PVA granules were higher than $295^{\circ} \mathrm{C}$, which was much higher than the decomposition temperature of $240{ }^{\circ} \mathrm{C}$ for pure PVA granules. Although, the 

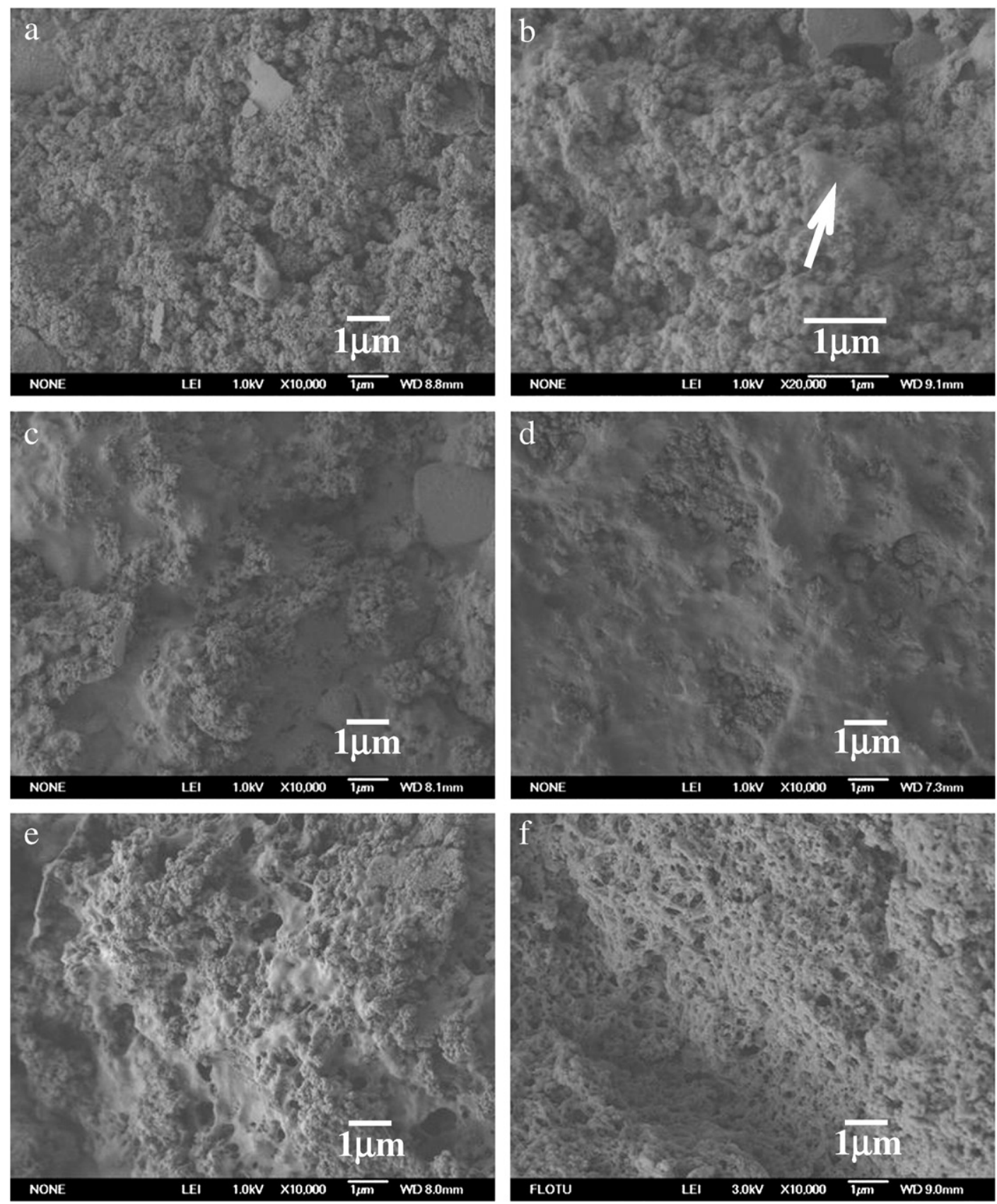

Fig. 3. SEM image of FAC-PVA granules at different cross-linked time. a: 10 min; b: 30 min; c: 2 h; d: 6 h; e: 12 h; f: 24 h.

peaks of FAC-PVA were somewhat different, which may have been caused by the different reaction quantity between PVA and FAC, the difference were very small compared to the peak difference between the FAC-PVA and pure PVA granules (about $55^{\circ} \mathrm{C}$ ). It can be inferred that FAC and PVA had formed a chemical bond in the FAC-PVA granules, instead of being just physically embedded. This made the FAC particles adhere tightly to the PVA polymer and the particles could not be easily leak out.

\subsection{Stability of the granules}

The effects of FAC and PVA mixture concentrations on the mechanical stability of the granules are shown in Fig. 7. Fig. 7 shows that the mechanical stability of the granules decreased with increased FAC concentration given a constant PVA concentration, which was also confirmed in the subsequent experiments. However, with increased PVA concentration, the mechanical stability increased, which is also shown in Fig. 7. However, the stability of almost all the granules was over $85 \%$.

Experiments showed that with decreased PVA concentration, large pores and holes formed, which caused the FAC particles to easily leak out. When the FAC concentration was increased and PVA concentration remained the same, the adhering strength between FAC and PVA decreased. Therefore, the increase of the FAC concentration and decrease of the PVA concentration leads to a decrease in the mechanical stability of the granules.

\subsection{Adsorption capacity of the granules}

The adsorption capacity of the granules with different FAC and PVA components was measured by detecting the amount of residual fluoride in the solution with a fluoride ion meter. The effect of FAC 

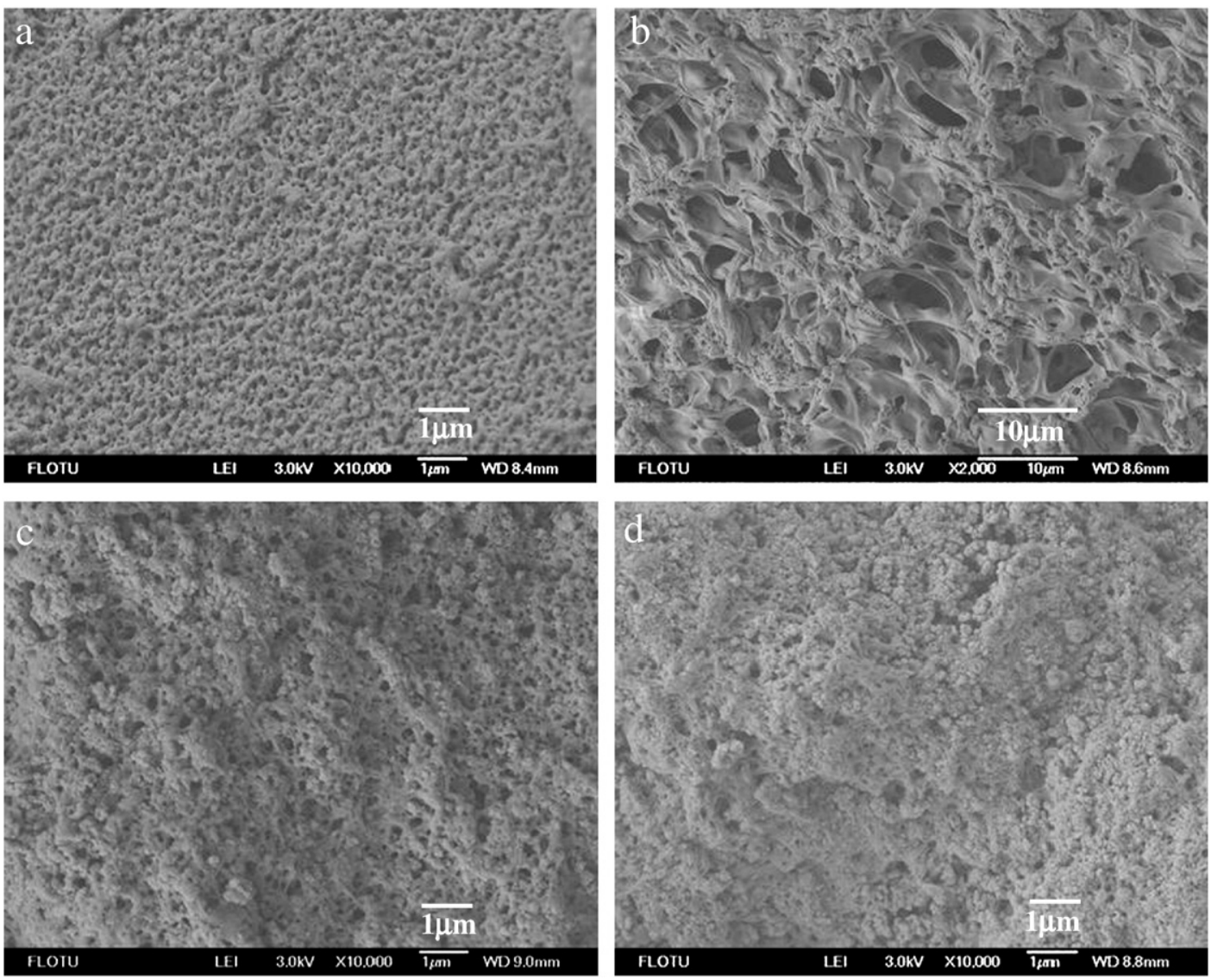

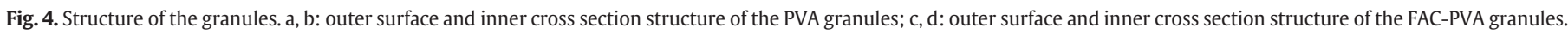

concentration on the fluoride adsorption capacity of the granules is confirmed and shown in Fig. 8. It shows that the adsorption capacity per unit mass of granules increased linearly with the FAC concentration at a set PVA concentration, which indicated that the efficiency of the FAC nano-adsorbents was almost constant. It was also determined that a higher FAC concentration in the granules will give granules a higher adsorption capacity.

Fig. 8 also shows that the fluoride adsorption capacity decreased with increased PVA concentration given set FAC concentrations. A lower PVA concentration in the suspension will give a higher adsorption capacity for the granules. However, a lower PVA concentration will result in lower granule stability, thus, a suitable PVA concentration would be one that is a balance between stability and adsorption capacity.
For an acceptable adsorption capacity and mechanical stability of the granules, a FAC concentration of $12 \%$ and PVA concentration of $7.5 \%$ for the suspension was suggested. Under this condition, spherical granules of 3-5 mm can be obtained. The granules have high hydraulic conductivity in a packed bed, high adsorption capacity, and high strength even when soaked in $\mathrm{NaOH}$ ( $\mathrm{pH} 12$ ) for over a month. With these granules, the fluoride adsorption capacity is $4.46 \mathrm{mg} / \mathrm{g}$ (granules) at pH 6.5 and initial fluoride concentration of $19 \mathrm{mg} / \mathrm{L}$.

The above results have demonstrated that the granulation of a FAC adsorbent can be achieved by using porous PVA as an adsorbent matrix. These granules can be used in packed beds for fluoride removal from drinking water. However, for its application in industry, the durability, regeneration and the cost all need to be further studied.

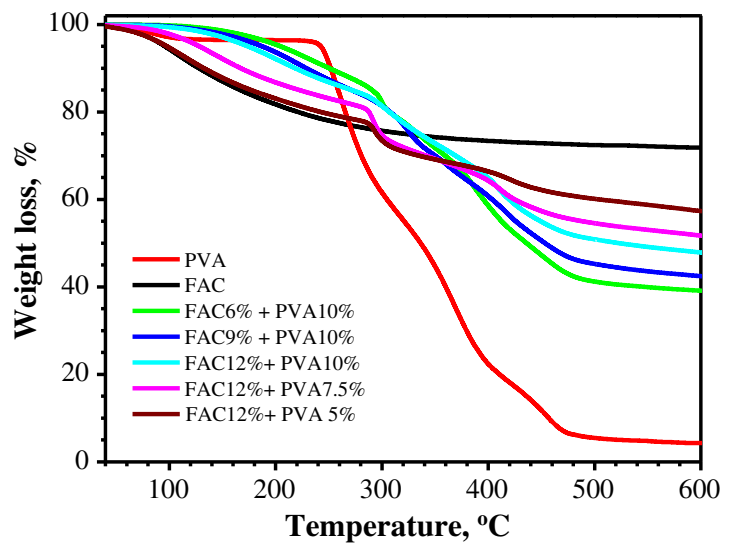

Fig. 5. TGA curves of different granules.

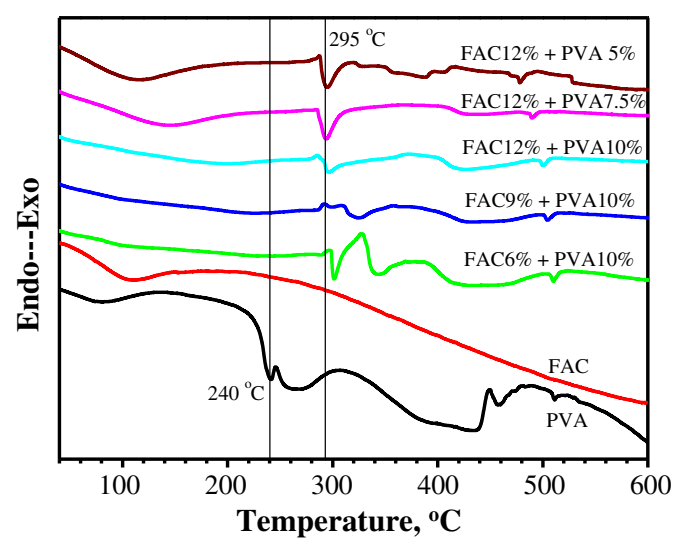

Fig. 6. DSC curves of different granules. 


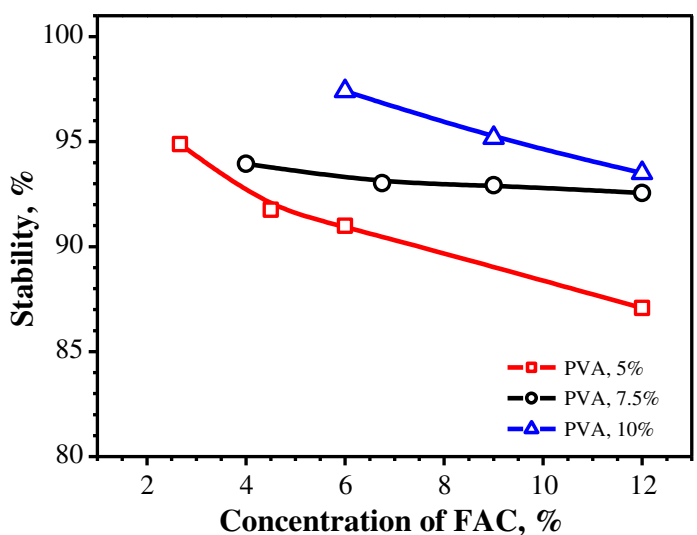

Fig. 7. Effect of FAC concentration on the stability of the granules.

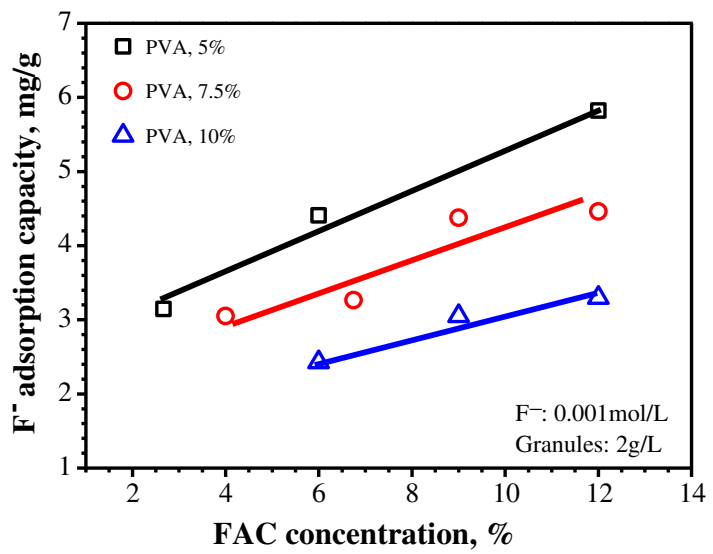

Fig. 8. Effect of FAC concentration on fluoride adsorption capacity.

\section{Conclusions}

FAC was granulated by immobilizing FAC in a porous polyvinyl alcohol matrix via cross-linking with boric acid, into spherical shapes of $3-5 \mathrm{~mm}$ in size. The $3-5 \mathrm{~mm}$ size gives the granules a high hydraulic conductivity in packed beds for fluoride removal from drinking water. Experiments showed that the FAC were embedded in the PVA in granule holes of about $10 \mu \mathrm{m}$, while the surface pores of the granules were only on the nano-scale, in a structure that supports high surface area for adsorption of fluoride ions. FAC and PVA had formed a chemical bond, which made the FAC tightly loaded on the porous structure of PVA. The mechanical stability of the granules increased with increased PVA concentration, and decreased with increased FAC concentration. A higher FAC concentration and lower PVA concentration produced a higher adsorption capacity of the granules. A FAC concentration of $12 \%$ and PVA concentration of $7.5 \%$ were suggested for the granulation and gave the granules an adsorption capacity of fluoride ions of $4.46 \mathrm{mg} / \mathrm{g}$ at $\mathrm{pH} 6.5$ and an initial fluoride concentration of $19 \mathrm{mg} / \mathrm{L}$.

\section{Acknowledgement}

The authors wish to express their appreciation of the financial support of this study by the National High Technology Research and Development Program of China (863 Program, No. 2007AA06Z319) and the National Natural Science Foundation of China (NSFC No. 20906055).

\section{References}

[1] Meenakshi, R.C. Maheshwari, Fluoride in Drinking Water and Its Removal, J. Hazard. Mater. 137 (1) (2006) 456-463.

[2] WHO, Guidelines for Drinking-Water Quality, 1st Addendum to Third Edition, 2006, http://www.who.int/water_sanitation_health/dwq/gdwq3rev/en/.

[3] M.S. Onyango, H. Matsuda, T. Alain, Chapter 1 fluoride removal from water using adsorption technique, Adv. Fluorine Sci. (2006).

[4] M.A. Menkouchi Sahli, S. Annouar, M. Tahaikt, M. Mountadar, A. Soufiane, A. Elmidaoui, Fluoride removal for underground brackish water by adsorption on the natural chitosan and by electrodialysis, Desalination 212 (1-3) (2007) 37-45.

[5] H. Garmes, F. Persin, J. Sandeaux, G. Pourcelly, M. Mountadar, Defluoridation of groundwater by a hybrid process combining adsorption and donnan dialysis, Desalination 145 (1-3) (2002) 287-291.

[6] X.M. Wu, Y. Zhang, X.M. Dou, M. Yang, Fluoride removal performance of a novel Fe-Al-Ce trimetal oxide adsorbent, Chemosphere 69 (11) (2007) 1758-1764.

[7] T.L. Theis, R. Iyer, S.K. Ellis, Evaluating a new granular iron oxide for removing lead from drinking water, J. AWWA 84 (7) (1992) 101-105.

[8] M.J. Keyser, M. Conradie, M. Coertzen, J.C. Van Dyk, Effect of coal particle size distribution on packed bed pressure drop and gas flow distribution, Fuel 85 (1011) (2006) 1439-1445.

[9] C.H. Lai, C.Y. Chen, B.L. Wei, S.H. Yeh, Cadmium adsorption on goethite-coated sand in the presence of humic acid, Water Res. 36 (20) (2002) 4943-4950.

[10] S.L. Lo, T.Y. Chen, Adsorption of Se(IV) and $\mathrm{Se}(\mathrm{VI})$ on an iron-coated sand from water, Chemosphere 35 (5) (1997) 919-930.

[11] S.M. Maliyekkal, A.K. Sharma, L. Philip, Manganese-oxide-coated alumina: a promising sorbent for defluoridation of water, Water Res. 40 (19) (2006) 3497-3506

[12] J. Lukasik, Y.F. Cheng, F. Lu, M. Tamplin, S.R. Farrah, Removal of microorganisms from water by columns containing sand coated with ferric and aluminum hydroxides, Water Res. 33 (3) (1999) 769-777.

[13] C.H. Bolster, A.L. Mills, G.M. Hornberger, J.S. Herman, Effect of surface coatings, grain size, and ionic strength on the maximum attainable coverage of bacteria on sand surfaces, J. Contam. Hydrol. 50 (3-4) (2001) 287-305.

[14] M.S. Al-Sewailem, E.M. Khaled, A.S. Mashhady, Retention of copper by desert sands coated with ferric hydroxides, Geoderma 89 (3-4) (1999) 249-258.

[15] H.X. Wu, T.J. Wang, X.M. Dou, B. Zhao, L. Chen, Y. Jin, Spray coating of adsorbent with polymer latex on sand particles for fluoride removal in drinking water, Ind. Eng. Chem. Res. 47 (14) (2008) 4697-4702.

[16] Y.J. Wang, X.J. Yang, H.Y. Li, W. Tu, Immobilization of acidithiobacillus ferrooxidans with complex of PVA and sodium alginate, Polym. Degrad. Stab. 91 (10) (2006) 2408-2414.

[17] L.S. Zhang, W.Z. Wu, J.L. Wang, Immobilization of activated sludge using improved polyvinyl alcohol (PVA) gel, J. Environ. Sci. 19 (11) (2007) 1293-1297.

[18] Z.E. Long, Y.H. Huang, Z.L. Cai, Immobilization of acidithiobacillus ferrooxidans by a PVA-boric acid method for ferrous sulphate oxidation, Process Biochem. 39 (12) (2004) 2129-2133.

[19] B. Krajewska, Application of chitin-and chitosan-based materials for enzyme immobilizations: a review, Enzyme. Microbiol. Technol. 35 (2-3) (2004) 126-139.

[20] D. Bezbradica, B. Obradovic, I. Leskosek-Cukalovic, B. Bugarski, V. Nedovic, Immobilization of yeast cells in PVA particles for beer fermentation, Process Biochem. 42 (9) (2007) 1348-1351.

[21] A. Idris, N.A.M. Zain, M.S. Suhaimi, Immobilization of Baker's yeast invertase in PVA-alginate matrix using innovative immobilization technique, Process Biochem. 43 (4) (2008) 331-338.

[22] I.S. Chang, C.I. Kim, B.U. Nam, The influence of poly-vinyl-alcohol (PVA) characteristics on the physical stability of encapsulated immobilization media for advanced wastewater treatment, Process Biochem. 40 (9) (2005) 3050-3054.

[23] X. Li, T.J. Wang, Y. Jin, Granulation process for producing spherical particles of a rubber antioxidant in a water cooling tower, Chem. Eng. Technol. 29 (10) (2006) 1273-1280. 